\title{
CONSIDERAÇÕES PRÁTICAS ACERCA DA RESPONSABILIDADE OBJETIVA
}

\author{
PRACTICAL CONSIDERATIONS ABOUT STRICT LIABILITY
}

\author{
${ }^{1}$ Bruno de Almeida Lewer Amorim \\ ${ }^{2}$ César Fiuza
}

\section{RESUMO}

O presente artigo busca analisar se a prática da responsabilidade civil objetiva na seara das relações consumeristas reflete os avanços tão propalados pela doutrina ao longo dos séculos XIX e XX, sobretudo no que diz respeito à substituição do nexo de imputação da culpa pelo nexo de imputação do risco da atividade. Como método, serão analisadas as causas excludentes de responsabilidade previstas no Código de Defesa do Consumidor e as reconhecidas pela jurisprudência e doutrina. Em seguida, perscrutar-se-á se a aplicação jurisprudencial reflete uma responsabilidade calcada no risco ou se o fundamento do dever de reparar continua sendo a culpa.

\section{Palavras-Chave}

Código de Defesa do Consumidor; Código Civil; responsabilidade objetiva; responsabilidade subjetiva; culpa.

\section{SUMMARY}

The article aims to analyze if the practice of strict liability in consumer relations reflects the advances claimed by doctrine throughout the nineteenth and twentieth centuries, especially regard to the replacement of the imputation nexus of negligence for the nexus of activity risk. As a method, it will be analyzed the excluding causes of liability in the Consumer's Defense Code and those recognized by jurisprudence and doctrine. Thereafter, it will be analyzed whether the actual judicial practice reflects liability based on the risk or the foundation of the duty to repair still relies upon the imputation of negligence.

\section{Keywords}

Consumer's Defense Code; Civil Code; strict liability; subjective liability; negligence.

\footnotetext{
${ }^{1}$ Mestrando em Direito Privado pela Pontifícia Universidade Católica de Minas Gerais (PUC Minas), Belo Horizonte, Minas Gerais, Brasil. Especialista em Direito Civil Aplicado pela Pontifícia Universidade Católica de Minas Gerais (PUC Minas), Belo Horizonte, Minas Gerais, Brasil.Professor da Pós-Graduação em Direito de Empresa pela Pontifícia Universidade Católica de Minas Gerais (PUC Minas), Belo Horizonte, Minas Gerais, Brasil. Email: lewer.amorim@gmail.com

${ }^{2}$ Doutor em Direito pela Universidade Federal de Minas Gerais (UFMG), Belo Horizonte, Minas Gerais, Brasil. Professor de Direito Civil pela Universidade Federal de Minas Gerais (UFMG), Belo Horizonte, Minas Gerais, Brasil. Email: cesarfiuza@gmail.com
} 


\section{INTRODUÇÃO}

Muito se tem propalado, ao longo dos últimos anos, acerca da evolução da responsabilidade civil e da substituição do nexo de imputação da culpa pelo risco da atividade. Como fundamentos dessa mudança, são invocados os novos paradigmas do Direito Privado, que passaram a conceber, como centro do sistema jurídico, a Constituição, dissolvendo a clássica dicotomia entre Direito Público e Direito Privado. Essa mudança paradimática, por sua vez, coloca no centro de irradiação de valores e princípios do sistema jurídico a promoção da dignidade humana, amplamente tutelado pela Constituição de 1988.

Na seara das relações de consumo, a responsabilidade civil objetiva é consagrada, expressamente, pelo caput do art. 14 do Código de Defesa do Consumidor, o qual destaca que "o fornecedor de serviços responde, independente da existência de culpa, pela reparação dos danos causados aos consumidores por defeitos relativos à prestação dos serviços". Mais adiante, porém, em seu $\S 3^{\circ}$, o referido artigo menciona as denominadas hipóteses excludentes de responsabilidade, as quais, se demonstradas pelo fornecedor, o eximem do dever de reparar o dano. São elas: a) provar que o defeito não existe; b) provar que não colocou o produto ou serviço no mercado de consumo; c) provar a culpa exclusiva do consumidor ou de terceiro. Para além dessas hipóteses, doutrina e jurisprudência ainda reconhecem como causas excludentes não tipificadas: a) caso fortuito e força maior; b) risco do desenvolvimento. Igualmente, admitese a hipótese de culpa concorrente do consumidor para atenuar a responsabilidade do fornecedor.

Analisadas as hipóteses excludentes, assim como sua aplicação jurisprudencial, surge o questionamento se, de fato, ou seja, na prática judicial, sobraria espaço para a responsabilidade independente de culpa. Isso porque, embora as hipóteses excludentes contemplem situações de rompimento do nexo causal, a discussão da culpa parece ser a causa principal de exoneração da responsabilidade dos fornecedores, como evidenciam os julgados que serão analisados adiante. Na realidade, embora a dogmática tenha defendido ao longo dos anos os valores da solidarização dos riscos inerentes à sociedade de consumo e de busca pela reparação prioritária das vítimas de danos, o legislador menos, e, principalmente, a jurisprudência, em muitos casos, têm-se mantido ainda firmes no paradigma da responsabilidade subjetiva, como se demonstrará. 
Diga-se que o entendimento jurisprudencial não parece contradizer o senso de justiça e equidade vigente no próprio meio jurídico, como mostra o posicionamento favorável da doutrina. Aqui reside o ponto central deste trabalho. Não se propõe um juízo de valor acerca das causas excludentes de responsabilidade do fornecedor. Antes pelo contrário, há que defendê-las, a fim de não incorrer no risco integral do fornecedor. Não obstante, chama-se a atenção para o descompasso entre a teoria e a prática da responsabilidade objetiva, a qual evidencia um sentido subjetivo de justiça, muitas vezes, ainda atrelado à noção de culpa, quando, rigorosamente, não poderia estar. Ao que parece, os valores propalados pela doutrina da responsabilidade objetiva não refletem a prática jurisprudencial. Melhor dizendo, os valores proclamados pela doutrina da responsabilidade objetiva não parecem ter sido acolhidos sem reservas pela jurisprudência, que, timidamente, mantém viva a discussão de culpa na apuração da responsabilidade civil dos fornecedores. O que se discute, na maioria dos casos, como se verá abaixo, não é a quebra do nexo causal entre a conduta do fornecedor e o dano sofrido pelo consumidor. Mas sim a concorrência culposa do fornecedor para o dano em questão.

Acertadamente, doutrina e jurisprudência têm reconhecido a distinção entre fortuito externo e fortuito interno. O primeiro congrega fato imprevisível ou inevitável que não se relaciona à atividade do fornecedor, excluindo sua responsabilidade pelo evento danoso, por excluir a própria autoria, em última instância. O segundo também abrange fato imprevisível ou inevitável, mas que, por fazer parte dos riscos inerentes à atividade desempenhada pelo fornecedor, enseja sua responsabilização. Trata-se da aplicação da regra clássica: quem obtém os bônus deve arcar com os ônus. No entanto, em que pese a previsão do caput do art. 14, do CDC, a responsabilidade independente da apuração de culpa ainda parece, como se verá em muitos arestos, uma realidade distante na seara das relações de consumo.

\section{A RESPONSABILIDADE OBJETIVA NAS RELAÇÕES DE CONSUMO}

A responsabilidade civil passou por importantes transformações desde sua abordagem pelo Código Civil Francês de 1804, tudo em prol da necessidade de enfrentamento de novas modalidades de lesão a direitos, bem como de tutela de 'novos direitos' que se evidenciam conforme o caminhar da civilização humana e o desenvolvimento de novas formas de relacionamento entre os indivíduos. Nesse sentido, poder-se-ia falar num paradigma da 'culpa' ou da 'responsabilidade civil subjetiva', assim como num paradigma do 'risco' ou da 'responsabilidade civil objetiva'. A passagem de um para o outro decorre do surgimento e do enfrentamento de anomalias e da mudança dos valores sociais, conforme será analisado adiante. 
Essas mudanças - ou revoluções, como prefere Thomas Kuhn (1998, p. 12), acabam por lançar o desenvolvimento da ciência jurídica por outros rumos e caminhos, culminando com o surgimento de novas teorias, capazes de resolver as antinomias não superadas pelos paradigmas anteriores. Esse movimento é contínuo e constante.

O paradigma liberal impunha a prevalência do indivíduo e do patrimônio na ordem jurídica, estando o ordenamento privado voltado à defesa precípua das liberdades individuais e da propriedade privada. Sob a égide desses valores, os direitos individuais assumiam máxima importância, admitindo-se a interferência do Estado e sua intromissão no patrimônio privado somente naqueles casos estritos nos quais restasse evidenciada uma conduta culposa (lato sensu) do agente perpetrador do dano.

Uma das principais anomalias enfrentadas pelo paradigma da responsabilidade baseada na culpa foi o da mecanização do processo produtivo. Como às falhas do processo produtivo mecanizado e automatizado não se podia imputar culpa, que é elemento exclusivamente humano, milhares de vítimas passaram a ficar sem a devida reparação. Não havia como identificar quem agira com culpa. Por outro lado, a massificação das relações comerciais, intensificada ao longo dos séculos XIX e XX pelo desenvolvimento industrial, também lançou luz sobre as patentes insuficiências da teoria clássica da responsabilidade civil subjetiva. A massificação na produção de bens de consumo gerou a massificação de danos. Uma falha no processo produtivo poderia acarretar a fabricação defeituosa de milhares de produtos, os quais, por sua vez, poderiam lesar milhares de indivíduos.

De fato, a teoria clássica da culpa não apresentava respostas para essas anomalias, intensificadas com o advento da sociedade moderna e, mais tarde, já em meados do século XX, com o advento da sociedade de consumo. Não obstante, suas raízes históricas, políticas e sociais eram tão profundas, que muita resistência houve, e ainda há, diante dos movimentos que começaram a pregar o abandono, ou ao menos o aperfeiçoamento, da responsabilidade civil baseada na culpa.

Era a hora e o momento de admitir-se um novo paradigma. Entretanto, ao contrário do que pregava Kuhn, um paradigma não é simplesmente substituído por outro. Como observa Lakatos, mesmo diante de anomalias insuperáveis, as transformações não são completas. Aproveita-se muito do que já havia sido construído sob a égide do paradigma anterior. Além 
do que, pode-se dizer que essa mudança comumente é gradual, estando distante da ideia de “revolução científica” proposta por Kuhn (LAKATOS \& MUSGRAVE, 1979, p. 111).

No caso das transformações sofridas pelo instituto da responsabilidade civil clássica, a concepção lakatiana parece ter prevalecido. Uma primeira e singela mudança no paradigma da culpa é experimentada na Prússia, na primeira metade do século XIX. Em 1838, foi editada a lei prussiana que previa a responsabilidade objetiva em relação a danos causados na exploração de estradas de ferro. Por outros termos, o empregador respondia simplesmente em razão do exercício daquela atividade. No Direito Brasileiro, a primeira legislação a adotar a noção de presunção de culpa foi o Decreto $n^{\circ}$ 2861/1912, o qual atribui responsabilidade com culpa presumida àqueles que explorem o transporte ferroviário no país. Este decreto se encontra em vigor até hoje.3 Embora tal representasse inequívoco avanço, não se tratava ainda de uma responsabilidade sem culpa, mas sim de uma responsabilidade em que a culpa era presumida. Por conseguinte, o paradigma dominante da culpa, enquanto nexo de imputação da responsabilidade civil e condição para reparação do dano, continuava vigente.

Como dito, a teoria da culpa é construída pelos juristas clássicos, ao longo dos séculos XVIII e XIX, exercendo forte influência na elaboração do Código Civil Francês de 1804, o qual, por sua vez, influenciou diversas codificações ao redor do mundo. Por essa razão, não seria fácil abandoná-la. Mas essas transformações ainda não eram suficientes para promover o ideal de reparação integral dos danos injustos. Era preciso que a noção de culpa fosse abandonada de fato, ao menos em algumas situações, com a adoção de um novo paradigma. Josserand e Selleiles (apud AMORIM, 2016, p. 49), no final do século XIX, introduzem, então, a noção de "risco" como substituta da noção de "culpa", propondo a alteração do nexo de imputação da responsabilidade civil, acarretando a criação de uma modalidade objetiva de reparação de danos. A ideia central era que a responsabilidade passasse a ter fundamento no risco inerente à atividade desempenhada pelo causador do dano, não na sua culpa.

Quem dá nome a esse novo nexo de imputação da responsabilidade civil não é a Lei, mas a doutrina, sobretudo francesa. Alguns sujeitos, em razão do risco inerente à atividade que

\footnotetext{
${ }^{3}$ Vale notar que o Decreto das Estradas de Ferro (Dec. n. 2861/1912) não traz a expressão "independente de culpa". Essa interpretação foi construída pela doutrina, a partir da exegese de seu art. $1^{\circ}$, segundo o qual:

Art. $1^{\circ}$ - As estradas de ferro serão responsáveis pela perda total ou parcial, furto ou avaria das mercadorias que receberem para transportar.

Será sempre presumida a culpa e contra esta presunção só se admitirá alguma das seguintes provas.

$1^{\mathrm{a}}$ - caso fortuito ou força maior; [...] (grifamos)
} 
exercem, devem por ela se responsabilizar, independentemente de culpa, assegurando que vítimas de danos dela decorrentes sejam reparadas. O intuito é assegurar a devida reparação das vítimas numa sociedade na qual o risco está cada vez mais presente ${ }^{4}$.

A mudança paradigmática que ensejou a substituição do nexo de imputação da responsabilidade civil clássica, da culpa para o risco, não implicou o abandono da teoria da culpa. Muito pelo contrário, a responsabilidade civil objetiva ocupou os espaços necessários, como o das relações de consumo, o das relações ambientais, o das relações com o Estado etc., continuando a vigorar, nos demais casos, a responsabilidade subjetiva. É de se perguntar, todavia, se essa mudança teórica ensejou efetivas mudanças práticas na aplicação do instituto da responsabilidade civil, ou se, em muitos casos, as alterações ficaram restritas ao campo doutrinário.

Para responder a essa pergunta, ater-se-á, especificamente, à responsabilidade civil de consumo, isso por motivos estritamente metodológicos, com a finalidade de delimitar um campo de pesquisa e análise que permita conclusões gerais e uniformes.

Como visto, há, em suma, três momentos que marcam a evolução da responsabilidade civil: num primeiro momento, a responsabilidade depende, impreterivelmente, da demonstração de culpa; num segundo momento, doutrina e jurisprudência começam a reconhecer hipóteses nas quais há uma presunção de culpa, a qual, não obstante, pode ser afastada pelo agente causador do dano, em determinadas situações; num terceiro momento, surge a denominada responsabilidade objetiva ou responsabilidade independente de culpa, na qual o nexo de imputação da responsabilidade civil deixa de ser a culpa e passa a ser o risco. Nesse último caso, a discussão de culpa passa a ser irrelevante, vale dizer, mesmo que o causador do dano demonstre não ter agido culposamente, o dever de reparar manter-se-á incólume, bastando que haja o nexo causal entre a conduta ou a atividade por ele prestada e o dano.

Do próprio conceito de ato ilícito, derivam-se os requisitos essenciais para a ocorrência do dever de indenizar, quais sejam: a conduta antijurídica, o dano e o nexo de causalidade, ou seja, o liame existente entre a conduta antijurídica e o dano. Além disso, um quarto elemento deve ser apontado: o nexo de imputação, elemento subjetivo da conduta do agressor (culpa lato

\footnotetext{
${ }^{4}$ A esse respeito explica Arthur Rios: “[...] hoje a 'responsabilidade pelo dano' faz-nos abraçar o direito social, o solidarismo, onde o causador deve indenizar pelo simples fato e não pela vontade, que não interessa existente ou não, para a existência do dano, que continua o mesmo com ou sem ela" (RIOS, 1986, p. 81).
} 
sensu) ou o risco da atividade, a depender da modalidade - subjetiva ou objetiva - de responsabilidade civil.

Nas relações de consumo, a Lei $\mathrm{n}^{\circ}$ 8.078/90 impõe como regra a responsabilidade objetiva e como exceção a responsabilidade subjetiva. Precisamente quanto ao tema deste trabalho, a responsabilidade civil objetiva a ser analisada será aquela prevista nos arts. 12 e 14 do Código de Defesa do Consumidor. A questão que se propõe é se, na prática forense, a responsabilidade objetiva pura seria verdade ou apenas mito teórico.

No Código de Defesa do Consumidor, a responsabilização objetiva do fornecedor de produtos ou serviços é a regra, ou seja, é irrelevante se agiu com culpa ao exercer a sua atividade. Basta que o serviço ou produto fornecido tenha causado prejuízo ao consumidor. Não obstante, a despeito de privilegiar a responsabilidade objetiva, o CDC contém algumas hipóteses de exclusão dessa responsabilidade. São elas: i) a prova de que o defeito do produto ou serviço inexista (art. $12, \S 3^{\circ}, \mathrm{II}$, e art. $14, \S 3^{\circ}, \mathrm{I}$ ); ii) a prova de que o fornecedor não tenha colocado o produto no mercado (art. $12, \S 3^{\circ}, \mathrm{I}$ ); iii) a prova da culpa exclusiva do consumidor ou de terceiro (art. 12, §3 $3^{\circ}$ III, e 14, $\S 3^{\circ}$, II). Nessas hipóteses, há o rompimento do nexo causal entre a atividade do fornecedor (autoria) e o dano sofrido pelo consumidor, exonerando-se o primeiro de responsabilidade. De igual forma, o caso fortuito e a força maior, desde que constituam fortuito externo, apesar de não previstos pelo Código de Defesa do Consumidor, constituem hipóteses jurisprudencialmente reconhecidas de exclusão da responsabilidade do fornecedor, por também romperem o referido nexo causal. Nesse sentido já se manifestou o Superior Tribunal de Justiça:

ADMINISTRATIVO - RESPONSABILIDADE CIVIL - ASSALTO EM ESTAÇÃO DO METRÔ - CASO FORTUITO. 1. A empresa prestadora de serviço é responsável pelos danos causados ao usuário em decorrência do serviço ou de sua falta. 2. Foge do nexo de causalidade os eventos ocorridos em decorrência de caso fortuito ou força maior. 3. Assalto ocorrido nas escadas de acesso ao metrô não pode ser considerado como falta do serviço, equiparando-se a assalto ocorrido em transporte coletivo. 4. Recurso especial provido. (REsp 402.708/SP, Rel. Ministra ELIANA CALMON, SEGUNDA TURMA, julgado em 24/08/2004, DJ 28/02/2005).

AUTOMÓVEL. ROUBO OCORRIDO EM POSTO DE LAVAGEM. FORÇA MAIOR. ISENÇÃO DE RESPONSABILIDADE. O fato de o artigo $14, \S 3^{\circ}$ do Código de Defesa do Consumidor não se referir ao caso fortuito e à força maior, ao arrolar as causas de isenção de responsabilidade do fornecedor de serviços, não significa que, no sistema por ele instituído, não possam ser invocadas. Aplicação do artigo 1.058 do Código Civil. A inevitabilidade e não a imprevisibilidade é que efetivamente mais importa para caracterizar o fortuito. E aquela há de entender-se dentro de certa relatividade, tendo-se o acontecimento como inevitável em função do que seria razoável exigir-se. (REsp 120.647/SP, Rel. Ministro EDUARDO RIBEIRO, TERCEIRA TURMA, julgado em 16/03/2000, DJ 15/05/2000). 
Além da força maior e do caso fortuito, há ainda a teoria do risco do desenvolvimento e a culpa concorrente da vítima, hipóteses que também vêm sendo acolhidas pela jurisprudência como excludentes ou atenunates da responsabilidade do fornecedor. Nesse sentido:

AGRAVO REGIMENTAL NO AGRAVO DE INSTRUMENTO. RESPONSABILIDADE OBJETIVA. CULPA CONCORRENTE. AGRAVO REGIMENTAL IMPROVIDO. - Na responsabilidade objetiva é desnecessário discutir a culpa do agente, uma vez que sua responsabilidade independe de culpa; entretanto, pode-se discutir a culpa concorrente ou exclusiva da vítima. - Agravo regimental improvido. (AgRg no Ag 852.683/RJ, Rel. Ministro LUIS FELIPE SALOMÃO, QUARTA TURMA, julgado em 15/02/2011, DJe 21/02/2011).

Segundo Braga Netto, “a impossibilidade do conhecimento da periculosidade, porém, deve ser absoluta, para qualquer fornecedor, e não subjetiva, apenas para um ou alguns" (BRAGA NETTO, 2008, p. 232). Ressalte-se, por oportuno, que a prova incumbe ao fornecedor que deseje afastar sua responsabilidade, como bem estabelece o $\$ 3^{\circ}$, art. 14 do CDC, ao dispor que "o fornecedor de serviços só não será responsabilizado quando provar", prosseguindo o dispositivo legal com a enumeração das hipóteses excludentes tipificadas. Nesse ponto, porém, convém indagar se hipóteses de exclusão da responsabilidade do fornecedor, de certa forma, não esvaziariam a responsabilidade objetiva na seara das relações de consumo, mantendo no bojo da responsabilidade civil de consumo a discussão da culpa.

\section{ANÁLISE JURISPRUDENCIAL DAS HIPÓTESES DE EXCLUSÃO DA RESPONSABILIDADE OBJETIVA NAS RELAÇÕES DE CONSUMO}

Ao que parece, as já analisadas causas excludentes da responsabilidade do fornecedor acabam por reinserir a discussão da culpa na apuração da responsabilidade civil de consumo. Senão vejamos. É possível perceber que o próprio dispositivo legal (art. 14, § $3^{\circ}$, III, do CDC), menciona como excludentes a "culpa exclusiva do consumidor ou de terceiro". A discussão da culpa está, portanto, presente. Na ocorrência de fortuito externo, por exemplo, não há culpa do fornecedor, diante da ocorrência do dano, porque advindo de evento alheio a seu controle. Nesse sentido:

DIREITO CIVIL. BRIGA ENTRE ALUNAS NAS DEPENDÊNCIAS DE INSTITUIÇÃO DE ENSINO SUPERIOR. IMPREVISIBILIDADE E INEVITABILIDADE. CASO FORTUITO. INEXISTÊNCIA O DEVER DE VIGILÂNCIA. RESPONSABILIDADE CIVIL DA FACULDADE NÃO CARACTERIZADA. RECURSO NÃO PROVIDO.

1. No caso de inevitabilidade e imprevisibilidade da ocorrência do atos lesivos, em conjunto com ausência de culpa da faculdade, resta caracterizado o caso fortuito.

2. O caso fortuito é excludente de responsabilidade civil.

3. Diferentemente do que ocorre nas escolas, as faculdades não possuem o dever de vigilância sobre os seus alunos, em virtude destes já serem maiores de idade e responsáveis por seus atos. 
4. Exclui-se a responsabilidade da faculdade, tendo em vista que esta possui a obrigação de instruir e não de vigiar.

5. Prevalência dos Votos Vencedores. Recurso não provido. (TJPE. EI 2385113 PE 001331193.2012.8.17.0000, $1^{\circ}$ Grupo de Câmaras Cíveis, Rel. Agenor Ferreira de Lima Filho, j. em 19/12/2012) (grifos nossos).

AÇÃO INDENIZATÓRIA. TRANSPORTE RODOVIÁRIO. ASSALTO Á MÃO ARMADA NO INTERIOR DO ÔNIBUS. RESPONSABILIDADE OBJETIVA AFASTADA. FATO DE TERCEIRO - CASO FORTUITO - CAUSA EXCLUDENTE DA RESPONSABILIDADE CIVIL.

Não foi demonstrada ausência de cuidado, alteracão de rota ou qualquer atitude da requerida que tenha auxiliado ou colaborado para o ocorrido. Na verdade, trata-se de fato totalmente desvinculado à atividade prestada pela empresa de transporte. In casu, não existe nexo de causalidade, tratando-se de culpa exclusiva de terceiro (TJRS. Recurso Cível $\mathrm{n}^{\circ}$ 71003107364 RS, Rel. Luís Francisco Franco, J. em 23/11/2011) (grifos nossos).

Como se percebe, claramente, em muitos julgados, a discussão da culpa continua presente na responsabilidade civil de consumo, mesmo tendo ela por nexo de imputação o risco da atividade. Em outras palavras, na prática, a culpa acaba sendo muitas vezes discutida, levando a crer que as mudanças tão propaladas pela doutrina, quanto ao nexo de imputação da responsabilidade civil, tenham ficado apenas na teoria. Como demonstrado, em muitos julgados, as hipóteses excludentes de responsabilidade do fornecedor são tratadas mais em função da culpa, do que do nexo causal entre atividade e dano. É o que ocorre, v.g., com a aplicação da teoria do risco do desenvolvimento. Um dado medicamento, produzido por um fabricante, provoca efeitos colaterais gravíssimos e não informados aos usuários. Apesar disso, sendo impossível a demonstração da culpa da empresa farmacêutica, que não tinha como prever os riscos do medicamento em razão do estado atual da ciência, o prejuízo será imputado à própria vítima.

Na União Europeia, foi editada a Diretiva CEE 374/85, que faculta a adoção ou não do instituto do risco do densevolvimento pelos países membros. A maior parte deles acabou por adotá-lo, nos termos do art. $7^{\circ}$, da referida diretiva:

Art. $7^{\circ}$. O produtor não deverá ser responsabilizado como resultado desta Diretiva caso demonstre:

e) que o estado do conhecimento científico e técnico ao tempo em que colocou o produto em circulação não permitia detectar a existência do defeito.

No Brasil, o tema gera controvérsias e não há consenso na doutrina e na jurisprudência. Há decisões que reconhecem sua aplicação como causa excludente de responsabilidade e outros que não, como reproduzimos adiante:

RESPONSABILIDADE CIVIL. DEFEITO EM MEDICAMENTO. VIOXX. FATO DO PRODUTO. DIREITO DO CONSUMIDOR. RESPONSABILIDADE OBJETIVA. 
$O$ art. 12 do Código de Defesa do Consumidor estabelece como objetiva a responsabilidade do fornecedor pelo fato do produto. Nestes casos, o fabricante só não é responsável pelos danos invocados pelo consumidor quando comprova que não colocou o produto no mercado, que o defeito alegado não existe ou a culpa exclusiva do consumidor ou de terceiro.

Estudos que demonstraram a contribuição do medicamento para o aumento do risco de problemas cardíacos em pacientes que fizeram uso prolongado e comportamento da empresa posteriormente, com retirada do produto do mercado, que comprovam a existência do defeito. CONDIÇÕES PESSOAIS DO FALECIDO. CONTRIBUIÇÃO DO MEDICAMENTO PARA OCORRENCIA DO FALECIMENTO. NEXO DE CAUSALIDADE. PROVA TESTEMUNHAL. MÉDICO PESSOAL.

É certo que no caso específico tratado nos autos, há comprovação da utilização continuada do medicamento pelo período que gerava o aumento de risco, além da informação de que o paciente, após sua primeira consulta com seu médico particular, não sofreu com outras desordens no sistema cardíaco, até o ano de 2004, quando sofreu episódio de parada cardiorrespiratória e fibrilação ventricular, que evoluíram, posteriormente, para o falecimento. Após, portanto, ter tomado o medicamento Vioxx, de forma continuada, por um período maior do que 18 meses. Não há dúvida de que a causa específica, o fator principal, determinante da morte, em casos como este, não poderá ser exatamente determinada. A questão, no entanto, é que o aumento do risco gerado pelo Vioxx, que simplesmente determinou sua abolição do mercado, estava presente na equação que resultou na morte do marido da autora. E, como tal, insere-se no nexo de causalidade, na relação de causa e efeito. DANOS MORAIS QUE DECORREM DO PRÓPRIO FATO. DESNECESSIDADE DE COMPROVAÇÃO OBJETIVA. CRITÉRIOS DE FIXAÇÃO DO VALOR DA INDENIZAÇÃO. TERMO INICIAL DE INCIDÊNCIA DE JUROS MORATÓRIOS E CORREÇ̃̃O MONETÁRIA. REDISTRIBUIÇÃO DA SUCUMBÊNCIA. APELAÇÃO CÍVEL PROVIDA. (TJRS - Apelação Cível : AC 70048594907 RS, Comarca de Porto Alegre, Rel. Des. Marilene Bonzanini, j. em 19/12/2012).

O mesmo ocorre em situações nas quais o nexo causal, embora não seja pautado por um juízo de certeza, pode ser verificado mediante um juízo de probabilidade. A esse respeito, Facchini Neto apresenta relevante estudo, abordando as novas tendências da responsabilidade civil, quanto à flexibilização do nexo causal e de sua demonstração. $\mathrm{O}$ foco de seu estudo é a indústria fumígena, cuja responsabilidade pelos danos oriundos de seus produtos é constantemente afastada ao argumento de ausência de demonstração inequívoca e cabal do nexo causal e ausência de culpa do fornecedor, já que o fumante age em seu livre-arbítrio. Como demonstra Facchini, inúmeros países vêm abandonando o paradigma da certeza quanto ao nexo causal, para substituí-lo pelo paradigma da probabibilidade ou forte possibilidade do nexo causal. (FACCHINI NETO, 2016, passim). No Brasil, todavia, ainda continuamos vinculados à exigência de certeza na demonstração do nexo causal. A questão da discussão de culpa e do nexo causal direto ficam evidentes nos casos de força maior e fortuito nas relações de consumo. Os fornecedores exercem atividades de risco e se responsabilizam, independentemente de culpa, por esses riscos.

Tratando-se de fortuito interno, trabalha-se com a ideia de responsabilidade independentemente da apuração de culpa. Em verdade, o dano provém de fato imprevisível ou previsível e inevitável, alheio à vontade e ao controle do fornecedor, mas, por ser inerente aos 
riscos de sua atividade, deve ser por ele assumido, segundo a lógica de que quem colhe os bônus, deve suportar os ônus. O conteúdo desses riscos inerentes a cada atividade varia. Em várias situações (assalto à saída de banco, cancelamento de voo por mau tempo e outras), há a presença de causas excludentes da responsabilidade do fornecedor, seja o caso fortuito ou de força maior, seja o fato exclusivo de terceiro. Indaga-se, porém, se em todos esses casos imputar-se-ia à vítima responsabilidade por seu próprio prejuízo. Sendo afirmativa a resposta, pergunta-se onde estaria a responsabilidade objetiva na seara das relações consumeristas.

Nas hipóteses supramencionadas, pergunta-se se não se estaria discutindo a culpa do fornecedor pelo dano sofrido, tirando o foco de sua responsabilidade por riscos inerentes à atividade. Factualmente, se o defeito inexiste, se o produto não foi colocado no mercado pelo fornecedor ou se a culpa é exclusiva do consumidor, não há que falar em responsabilidade do fornecedor, até mesmo por questão de equidade, boa-fé e responsabilidade do consumidor por seus atos. Não obstante, as causas excludentes parecem ter sido ampliadas pela doutrina e pela jurisprudência a ponto de reintroduzir a discussão da culpa para a seara da responsabilidade civil de consumo. Nesse sentido, é importante uma breve incursão na jurisprudência pátria. $\mathrm{O}$ primeiro aresto cuida do atraso ou do cancelamento do transporte aéreo decorrente de más condições climáticas.

RECURSO INOMINADO. TRANSPORTE AÉREO. ALTERAÇÃO DE VOO EM DECORRÊNCIA DE MAU TEMPO. ALEGAÇÃO DE CONDIÇÕES CLIMÁTICAS INAPROPRIADAS QUE RESTOU DEVIDAMENTE COMPROVADA. DANO MORAL INOCORRENTE. FORÇA MAIOR A EXCLUIR A ILICITUDE DO ATO. RECURSO PROVIDO (TJRS. Recurso Cível No 71004762647, Terceira Turma Recursal Cível, Turmas Recursais, Relator: Silvia Muradas Fiori, Julgado em 08/05/2014) grifos nossos.

Nesse caso, não há responsabilidade objetiva da companhia aérea. O que há, em verdade, é uma presunção de culpa, a qual, todavia, pode ser ilidida pela empresa, caso demonstrada má condição climática. Remetendo à análise feita anteriormente, o raciocínio empregado no julgado remete ao segundo momento da responsabilidade civil, calcada na presunção de culpa. O julgado, portanto, não reconhece a responsabilidade objetiva nesse caso, centrando sua fundamentação entorno da discussão da culpa da companhia aérea.

O mesmo ocorre quando o atraso decorre da greve de funcionários, fato que é tido, por inúmeras decisões, como fortuito externo, excludente da responsabilidade da companhia aérea.

RESPONSABILIDADE CIVIL. AÇÃO DE INDENIZAÇÃO POR PERDAS E DANOS. ATRASO DE VÔO. GREVE DOS FUNCIONÁRIOS. CASO FORTUITO EXTERNO. EXCLUDENTE DE RESPONSABILIDADE DA EMPRESA AÉREA. IMPROCEDÊNCIA DA APELAÇÃO. MANUTENÇÃO DA SENTENÇA (TJRN, AC 27394 RN 2001.002739-4, $2^{\text {a }}$ Câmara Cível, Des. Cláudio Santos, DJE 09/07/2005). 
No caso em questão, o TJRN exonerou de responsabilidade o transportador ao argumento de que este não foi "conivente ou omisso com relação aos eventos danosos ocorridos", que decorreram da greve dos funcionários. Ora, conivência e omissão compõem a noção de culpa.

Da mesma forma, no caso de assalto ocorrido nas adjacências (saída) de agência bancária, mas não em seu interior, a jurisprudência tem entendido inexistir responsabilidade por parte da instituição bancária.

CIVIL. INDENIZAÇÃO. CÓDIGO DO CONSUMIDOR. CLIENTE VÍTIMA DE ASSALTO. RESPONSABILIDADE CIVIL. SAQUE DE DINHEIRO EM AGÊNCIA BANCÁRIA. ASSALTO FORA DAS DEPENDÊNCIAS DO BANCO. AUSÊNCIA DE NEXO CAUSAL. DEVER DE INDENIZAR INEXISTENTE. IMPROCEDÊNCIA 01. A RESPONSABILIDADE CIVIL EXTRACONTRATUAL ACARRETA O DEVER DE INDENIZAR QUANDO HÁ O FATO OU A CONDUTA, O DANO E O NEXO DE CAUSALIDADE ENTRE ELES. 02. INEXISTINDO O VÍNCULO DE CAUSA E EFEITO, IMPUTÁVEL AO BANCO, JÁ QUE O ASSALTO OCORREU NO EXTERIOR DA AGÊNCIA BANCÁRIA, O DANO NÃO LHE PODE SER IMPUTADO, JÁ QUE PARA ELE NÃO CONTRIBUIU, A MENOS QUE SE QUEIRA ADOTAR A TEORIA DA EQUIVALÊNCIA DOS ANTECEDENTES, QUE, ENTRETANTO, NÃO É ACOLHIDA EM NOSSO DIREITO. 03. RECURSO DESPROVIDO.UNÂNIME (TJDFT. APL 40007520088070007 DF 000400075.2008.807.0007, Rel. ROMEU GONZAGA NEIVA, 5 Turma Cível, DJE 15/03/2011).

A situação será outra, caso o assalto ocorra no interior da agência:

AÇÃO DE INDENIZAÇÃO. DANOS MATERIAIS. DANOS MORAIS. ASSALTO NO INTERIOR DE AGÊNCIA BANCÁRIA.

1. Constitui defeito no serviço a ocorrência de assalto no interior de agência bancária. Fortuito interno em que o Banco responde independentemente de culpa.

2. Valor da indenização por danos morais, arbitrada em $\mathrm{R} \$ 5.000,00$ (cinco mil reais), em consonância com os elementos fáticos retratados nos autos e com os princípios da proporcionalidade e razoabilidade. Recursos de apelação não providos (TJSP. APL 10274982620158260100 SP 1027498-26.2015.8.26.0100, Rel. Roberto Mac Cracken, 22 Câmara de Direito Privado, DJE 16/12/2015).

Já no caso de assalto em posto de combustíveis, entendeu o STJ tratar-se de fortuito externo, eximindo de responsabilidade o fornecedor de combustível.

RECURSO ESPECIAL - DIREITO CIVIL E CONSUMIDOR - RESPONSABILIDADE CIVIL - INDENIZAÇÃO POR DANOS MORAIS E MATERIAIS - FORNECEDOR - DEVER DE SEGURANÇA - ARTIGO 14, CAPUT, DO CDC - RESPONSABILIDADE OBJETIVA POSTO DE COMBUSTÍVEIS - OCORRÊNCIA DE DELITO - ROUBO -CASO FORTUITO EXTERNO - EXCLUDENTE DE RESPONSABILIDADE - INEXISTÊNCIA DO DEVER DE INDENIZAR - RECURSO ESPECIAL IMPROVIDO.

I - E dever do fornecedor oferecer aos seus consumidores a segurançana prestação de seus serviços, sob pena, inclusive, deresponsabilidade objetiva, tal como estabelece, expressamente, opróprio artigo $\underline{14}$, "caput", do $\underline{\mathrm{CDC}}$.

II - Contudo, tratando-se de postos de combustíveis, a ocorrência dedelito (roubo) a clientes de tal estabelecimento, não traduz, emregra, evento inserido no âmbito da prestação específica 
docomerciante, cuidando-se de caso fortuito externo, ensejando-se, porconseguinte, a exclusão de sua responsabilidade pelo lamentávelincidente.

III - O dever de segurança, a que se refere o $\S 1^{\circ}$, do artigo 14 , doCDC, diz respeito à qualidade do combustível, na segurança dasinstalações, bem como no correto abastecimento, atividades,portanto, próprias de um posto de combustíveis.

IV - A prevenção de delitos é, em última análise, da autoridade pública competente. É, pois, dever do Estado, a proteção dasociedade, nos termos do que preconiza o artigo 144, da Constituiçãoda República.

V - Recurso especial improvido. (REsp 1243970 SE 2011/0056793-5, Ministro MASSAMI UYEDA, Terceira Turma, DJe 10/05/2012).

No caso do fornecimento de energia elétrica, o entendimento jurisprudencial é o mesmo.

\begin{abstract}
APELAÇÃO CÍVEL. DIREITO CIVIL. CONSUMIDOR. AÇÃO DE PROCEDIMENTO COMUM ORDINÁRIO. ALEGAÇÃO DE INTERRUPÇÃO NO SERVIÇO DE ENERGIA ELÉTRICA POR 20 HORAS EM RAZÃO DE FORTES CHUVAS OCORRIDAS EM TODA A REGIÃO ONDE RESIDE A AUTORA. SENTENÇA DE IMPROCEDÊNCIA. FATO FORTUITO EXTERNO QUE EXCLUI A RESPONSABILIDADE DA CONCESSIONÁRIA. (TJRJ. APL 21759373920118190021, Comarca de Duque de Caxias, Rel. MARCELO CASTRO ANATOCLES DA SILVA FERREIRA, VIGÉSIMA TERCEIRA CÂMARA CÍVEL CONSUMIDOR, DJE 19/08/2014).
\end{abstract}

No caso da adulteração de cheque por falsário, a jurisprudência também tem entendido pela exclusão da responsabilidade da instituição bancária, condicionando a responsabilidade do fornecedor apenas aos casos em que "evidenciada negligência e contribuição para a constituição do dano":

DIREITO DO CONSUMIDOR. AÇÃO DE INDENIZAÇÃO POR DANO MATERIAL E MORAL. FALSÁRIO. ADULTERAÇÃO DE CHEQUE. APRESENTAÇÃO PARA DESCONTO. INSTITUIÇÃO FINANCEIRA. FATO DE TERCEIRO. EXCLUSÃO DA RESPONSABILIDADE. ARTIGO 14, § $3^{\circ}$, INCISO II DO CDC. INEXISTÊNCIA DE PROVA DA NEGLIGÊNCIA DO BANCO E DE CONTRIBUIÇÃO PARA CONSUMAÇÃO DA FRAUDE. PEDIDOS IMPROCEDENTES. 1. Fundando-se a pretensão indenizatória proposta em face da instituição financeira na adulteração de cheque apresentado para pagamento/compensado, desvela-se autêntica hipótese de fato de terceiro, configurador de fortuito externo à atividade bancária, restando rechaçada a responsabilidade objetiva pura e simples, de maneira que sua responsabilização somente se concretiza caso evidenciada negligência e contribuição para a constituição do dano, aplicada a excludente prevista no artigo 14, § $3^{\circ}$, inciso II do CDC (TJMG - Apelação Cível 1.0194.10.011846-3/001, Relator(a): Des.(a) Otávio Portes , $16^{\mathrm{a}}$ CÂMARA CÍVEL, julgamento em 07/08/2013, publicação da súmula em 19/08/2013).

Data venia, o entendimento jurisprudencial, no caso, não parece ser o mais acertado, de vez que a adulteração de cheques representa violação ao sistema de segurança da própria instituição bancária, que não foi capaz de identificar a fraude, envolvendo falha direta do fornecedor. 
No caso do transporte de passageiros, a situação é ainda mais curiosa. Isso porque, o Código Civil, ao tratar do transporte de pessoas, prevê a responsabilidade objetiva do transportador, não admitindo o fato de terceiro como excludente.

Art. 735. A responsabilidade contratual do transportador por acidente com o passageiro não é elidida por culpa de terceiro, contra o qual tem ação regressiva. (grifamos)

Neste caso, o Código Civil estatui legítima responsabilidade objetiva do transportador. Não obstante, na seara das relações de consumo, a jurisprudência vem admitindo o fato de terceiro como excludente da responsabilidade do fornecedor, como evidenciam os julgados adiante.

DIREITO CIVIL. AÇÃO DE INDENIZAÇÃO POR DANOS MATERIAIS E MORAIS. SERVIÇO DE TRANSPORTE. ASSALTO A MÃO ARMADA. RESPONSABILIDADE DA TRANSPORTADORA. NÃO CABIMENTO. CASO FORTUITO EXTERNO. 1.

Consoante precedentes deste Tribunal e do Superior Tribunal de Justiça, o assalto a mão armada ocorrido durante a execução de serviço de transporte caracteriza-se como força maior ou caso fortuito, de modo que permanece afastada a responsabilidade da transportadora em indenizar os danos morais e materiais ocorridos. 2. Recurso de Apelação conhecido e não provido. (TJDFT.

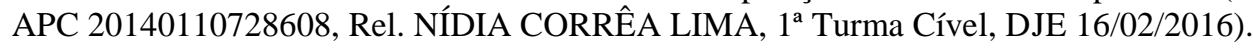

RESPONSABILIDADE CIVIL. DANOS MORAIS. CÓDIGO DE DEFESA DO CONSUMIDOR. SERVIÇO DE TRANSPORTE COLETIVO. IMPROPÉRIOS DIRIGIDOS POR TERCEIRO À USUÁRIA DO SERVIÇO. IRRESPONSABILIZAÇÃO DA EMPRESA DE TRANSPORTE CONFIGURADA. FATO DE TERCEIRO COMO EXCLUDENTE DA RESPONSABILIDADE CIVIL. SENTENÇA REFORMADA.

1. A RESPONSABILIDADE OBJETIVA DA EMPRESA DE TRANSPORTE COLETIVO DE PASSAGEIROS PODERÁ SER ELIDIDA POR FATO IMPUTÁVEL EXCLUSIVAMENTE À VÍTIMA OU A TERCEIRO. EXEGESE DO ARTIGO 14, PAR.3ํㅡ. II, IN FINE.

2. FATO DE TERCEIRO, ESTRANHO AO OBJETO DO CONTRATO DE TRANSPORTE, É RAZÃO, POR SI SÓ, PARA EXCLUSÃO DO NEXO DE CAUSALIDADE E, EM CONSEQÜÊNCIA, DA RESPONSABILIDADE OBJETIVA DA EMPRESA DE TRANSPORTE, POR FATOS ILÍCITOS OCORRIDO NO INTERIOR DE ÔNIBUS DE TRANSPORTE COLETIVO DE PASSAGEIROS.

3. CONSTITUI CAUSA EXCLUDENTE DE RESPONSABILIDADE DA EMPRESA TRANSPORTADORA FATO CAUSADO POR TERCEIRO, INTEIRAMENTE ESTRANHO AO TRANSPORTE EM SI. PRECEDENTE DA SEGUNDA SEÇÃO DO STJ. (STJ, RESP 262.682/MG, 4 ${ }^{\mathrm{a}}$ T., REL. MIN. BARROS MONTEIRO, DJU 20.06.2005). SENTENÇA REFORMADA (TJDFT. ACJ 20040810052906 DF, Rel. JOSÉ GUILHERME DE SOUZA, Primeira Turma Recursal dos Juizados Especiais Cíveis e Criminais do D.F., DJU 29/11/2006).

Trata-se de patente contrassenso. Neste caso, o Código Civil, que regula relações entre iguais, traz regramento mais benéfico para o passageiro do que o Código de Defesa do Consumidor, voltado à proteção do vulnerável. A alusão à regra disposta no art. $14, \S 3^{\circ}$, III do CDC - fato de terceiro, viola a noção de diálogo das fontes, fugindo da busca pela norma mais protetiva do consumidor e traduzindo patente contradição na interpretação e aplicação do ordenamento consumerista. 
De início, pautada na Súmula 187 do Supremo Tribunal Federal, a jurisprudência vinha entendendo que o transportador era responsável por indenizar o passageiro ferido ou roubado no interior de veículo que realizava o transporte coletivo, em razão de fato praticado por terceiro. Com o tempo, porém, o entendimento jurisprudencial alterou-se, passando a se firmar no sentido de considerar que o fato de terceiro, nos contratos de consumo, caracteriza-se como cláusula excludente de responsabilidade, prevista no $\S 3^{\circ}$ do art. 14, do CDC. Destarte, como ressalta o TJRN, em acórdão proferido em 2005, “a jurisprudência só tem responsabilizado o transportador quando este é conivente com relação aos eventos danosos ocorridos" ${ }^{\text {. Nesse }}$ sentido, não há dúvidas de que a discussão da culpa continua condicionando a reparação nas relações de consumo, mesmo tratando-se de responsabilidade objetiva. Até o STJ, ainda que de maneira mais restrita, tem admitido o fato de terceiro como excludente da responsabilidade do transportador nas relações de consumo:

AGRAVO REGIMENTAL. RESPONSABILIDADE CIVIL POR ACIDENTE AUTOMOBILÍSTICO. CONTRATO DE TRANSPORTE DE PASSAGEIROS. FATO DE TERCEIRO CONEXO AOS RICOS DO TRANSPORTE. RESPONSABILIDADE OBJETIVA NÃO AFASTADA. SÚMULA 187/STF. INTERESSE PROCESSUAL. SÚMULA 07. AGRAVO IMPROVIDO.

1. Esta Corte tem entendimento sólido segundo o qual, em se tratando de contrato de transporte oneroso, o fato de terceiro apto a afastar a responsabilidade objetiva da empresa transportadora é somente aquele totalmente divorciado dos riscos inerentes ao transporte.

2. O delineamento fático reconhecido pela justiça de origem sinaliza que os óbitos foram ocasionados por abalroamento no qual se envolveu o veículo pertencente à recorrente, circunstância que não tem o condão de afastar o enunciado sumular n. 187 do STF: a responsabilidade contratual do transportador, pelo acidente com o passageiro, não é elidida por culpa de terceiro, contra o qual tem ação regressiva. (...)

4. Agravo regimental improvido (AgRg no Ag 1083789 MG 2008/0176975-4, Ministro LUIS FELIPE SALOMÃO, Quarta Turma, DJe 27/04/2009).

Outrossim, o STJ reconhece como casos de "fortuito externo", excludentes da responsabilidade: a) assalto a mão armada no interior de ônibus coletivo (4 $4^{\mathrm{a}}$ Turma, $\mathrm{AgRg}$ no REsp 620259, j. em 15/10/2009); b) roubo de mercadoria transportada ( $3^{\text {a }}$ Turma, REsp 904733, j. em 09/08/2007); c) bala perdida que atinge passageiro no interior de ônibus de transporte coletivo (4 $4^{\mathrm{a}}$ Turma, REsp 613402, j. em 15/04/2004); d) arremesso de pedra, de fora de trem, causando lesões em passageiro ( $3^{\text {a }}$ Turma, REsp 154311, j. em 10/04/2001); e) assalto em estação de metrô (2 $2^{\mathrm{a}}$ Turma, REsp 402708, j. em 24/08/2004).

\footnotetext{
${ }^{5}$ TJRN, AC 27394 RN 2001.002739-4, 2 2 Câmara Cível, Des. Cláudio Santos, DJE 09/07/2005.
} 
Pergunta-se, portanto, como ficaria a responsabilidade objetiva do fornecedor nos casos de fortuito interno, já que, a maioria dos casos reconhecidos como fortuito interno parecem decorrer mais de ação ou culpa direta do fornecedor do que propriamente de eventos imprevisíveis afetos a sua atividade. Como exemplo, pode-se citar o assalto ocorrido dentro de agência bancária. A responsabilidade da instituição bancária advém da falha direta em sua segurança, sendo totalmente previsível a ocorrência de assaltos em estabelecimentos dessa natureza. Em razão da falha de segurança do banco, os consumidores assaltados são indenizados, não propriamente pela ocorrência de responsabilidade independente de culpa. $\mathrm{O}$ mesmo raciocínio se aplica às fraudes bancárias perpetradas por hackers e crackers, quando resta igualmente evidenciada falha de segurança por parte da instituição, salvo culpa exclusiva ou concorrente do consumidor. Por conseguinte, mesmo na identificação das hipóteses de fortuito interno, a jurisprudência permanece perscrutando a culpa, direta ou indireta, do fornecedor, afastando a responsabilidade objetiva de quaisquer repercussões práticas significativas.

Como dito, não se está analisando ou criticando a justeza da jurisprudência ou das próprias previsões legais. Antes pelo contrário, é de se afastar o risco integral. Todavia, pela presente análise, busca-se demonstrar o verdadeiro descompasso entre a teoria e a prática da responsabilidade objetiva. A partir da observação da legislação vigente e da jurisprudência, é possível perceber que a discussão da culpa continua viva na apuração da responsabilidade civil de consumo, muito embora marcada por nova distribuição do ônus probatório e presunções iuris tantum.

De outra perspectiva, e aqui se faz um juízo de valor, a flexibilização do nexo causal pode conduzir à necessária ampliação do rol das situações de fortuito interno, transferindo, de fato, para o fornecedor, a responsabilidade inerente a sua atividade, a qual lhe gera bônus, tornando-o responsável pelos ônus. Estes, em muitos casos, não podem e não devem ser transferidos para o consumidor, sob pena de se impor à vítima a responsabilidade por seu próprio prejuízo. Se em muitos casos não se pode imputar culpa ao fornecedor, à vítima muito menos.

Assim, embora sejam adequadas as causas excludentes de responsabilidade do fornecedor estatuídas pelo Código de Defesa do Consumidor, bem como aquelas majoritariamente reconhecidas pela doutrina e pela jurisprudência, acredita-se que a definição de fortuito interno necessite de urgente reconfiguração, de modo a se coadunar com a ideia de 
risco da atividade e possibilitar, de fato, o reconhecimento de uma responsabilidade independente de culpa do fornecedor, enquanto promoção do ideal de proteção da parte vulnerável na relação de consumo.

\section{CONCLUSÃO}

Embora o presente artigo não pretenda esgotar o tema, é possível perceber certo descompasso entre teoria e prática da responsabilidade objetiva na seara das relações de consumo. Não obstante o art. 14, caput, adotar a responsabilidade objetiva como a regra nas relações de consumo, seu $\$ 3^{\circ}$, assim como doutrina e jurisprudência, cuidaram de diminuir o alcance de seu comando, reinserindo, em muitos casos, a discussão da culpa no âmbito da responsabilidade de consumo. Mais do que romper o nexo causal, as hipóteses excludentes evidenciam a ausência de concorrência culposa do fornecedor para o dano. Aliás, como demonstrado, em muitas situações, o nexo causal entre a conduta do fornecedor e o dano é evidente, mas, ainda assim, diante da ausência de concorrência culposa para o dano, a responsabilidade do fornecedor é excluída. É o caso de atrasos de voo decorrentes de greves de funcionários da própria companhia aérea, ou de assaltos no interior de ônibus de transporte coletivo de passageiros. Ambas as situações refletem problemas de organização ou segurança, que impactam diretamente na prestação do serviço pelo fornecedor, ocasionando danos ao consumidor. Não obstante, o dever de reparar é afastado, deixando-se para a vítima o ônus da arcar com seu próprio prejuízo.

Embora seja válidas e necessárias as hipóteses excludentes da responsabilidade objetiva dos fornecedores, é de se questionar até que ponto a extensão atual dessas causas não esvaziaria o instituto da responsabilidade objetiva, deixando a descoberto os interesses da parte vulnerável dessa relação, o consumidor. Certo é que, nessas situações, o dano existe, decorre de uma atividade explorada com fins lucrativos pelos fornecedores, e, apesar disso, os ônus são transferidos à própria vítima. $\mathrm{O}$ fornecedor fica com os bônus da atividade, enquanto o consumidor assume os riscos e os ônus. Outrossim, como visto, há uma linha tênue e turva entre o fortuito interno e o fortuito externo. Nesse ponto, reside uma das principais oportunidades de se proteger de fato o consumidor e de se aplicar a teoria objetiva. Todavia, parte da jurisprudência, restritiva e conservadora, atrelada à exigência de um nexo causal direto e inequívoco, tem contribuído para a ampliação das hipóteses de fortuito externo e restrição demasiada do fortuito interno. 
Com esse cenário, a discussão continua viva, sendo a responsabilidade objetiva, em muitos casos, apenas um 'mito' na seara das relações de consumo. O que se percebe, enfim, é que a responsabilidade objetiva é marcada pela discrepância de entendimentos sobre uma mesma situação, sobretudo no âmbito jurisprudencial. O que parece evidente, todavia, é que, na apuração da responsabilidade do fornecedor, a miúde ocorre a análise da culpa dos envolvidos, sobretudo do agente causador do dano, que pode afastar a sua responsabilidade, nas hipóteses de culpa exclusiva do consumidor ou de terceiro, ou a ocorrência de fortuito. Resta claro, portanto, que a discussão de culpa continua viva, mesmo na seara da responsabilidade civil objetiva, ainda que residualmente.

\section{REFERÊNCIAS}

AMORIM, Bruno de Almeida Lewer. Pontos de interseção entre o direito civil e o direito do consumidor - Diálogo das fontes. In: Revista Luso-Brasileira de Direito do Consumo. Volume VI, número 21, março de 2016. Curitiba: Bonijuris.

BENJAMIN, Antonio Herman V.; MARQUES, Cláudia Lima; BESSA, Leonardo Roscoe. Manual de direito do consumidor. 5. ed., São Paulo: Revista dos Tribunais, 2013.

BRAGA NETTO, Felipe Peixoto. Responsabilidade civil. São Paulo: Saraiva, 2008.

BRASIL. Superior Tribunal de Justiça. REsp 402.708/SP, Rel. Ministra ELIANA CALMON, SEGUNDA TURMA, julgado em 24/08/2004, DJ 28/02/2005

. Superior Tribunal de Justiça. REsp 120.647/SP, Rel. Ministro EDUARDO RIBEIRO, TERCEIRA TURMA, julgado em 16/03/2000, DJ 15/05/2000

Superior Tribunal de Justiça. AgRg no Ag 852.683/RJ, Rel. Ministro LUIS FELIPE

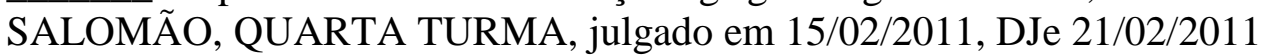

Superior Tribunal de Justiça. REsp 1243970 SE 2011/0056793-5, Ministro MASSAMI UYEDA, Terceira Turma, DJe 10/05/2012

Superior Tribunal de Justiça. AgRg no Ag 1083789 MG 2008/0176975-4, Ministro LUIS FELIPE SALOMÃO, Quarta Turma, DJe 27/04/2009 
CAVALIERI FILHO, Sérgio. O direito do consumidor no limiar do século XXI. In: Revista Trimestral de Direito Civil, v. 2, São Paulo, abril./jun. 2000.

DA SILVA, Wilson Melo. Responsabilidade sem culpa. 2. ed., São Paulo: Saraiva, 1974.

DISTRITO FEDERAL. Tribunal de Justiça do Distrito Federal e Territórios. APC 20140110728608, Rel. NÍDIA CORRÊA LIMA, $1^{\mathrm{a}}$ Turma Cível, DJE 16/02/2016.

. Tribunal de Justiça do Distrito Federal e Territórios. ACJ 20040810052906

DF, Rel. JOSÉ GUILHERME DE SOUZA, Primeira Turma Recursal dos Juizados Especiais Cíveis e Criminais do D.F., DJU 29/11/2006.

FACCHINI NETO, Eugênio. A relativização do nexo de causalidade e a responsabilização da indústria do fumo - a aceitação da lógica da probabilidade. Civilística.com. a. 5. N. 1. 2016.

FIUZA, César. Direito civil: curso completo. 18. ed., São Paulo: Revista dos Tribunais, 2015.

GONÇALVES, Carlos Roberto. Responsabilidade civil. 8. ed., São Paulo: Saraiva, 2003.

ILDEFONSO, Carlos Brandão. Responsabilidade objetiva - verdade ou mito? Belo Horizonte: D’Plácido, 2014.

KUHN, Thomas Samuel. A estrutura das revoluções científicas. 5. ed., São Paulo: Perspectiva, 1998.

LAKATOS, Imre \& MUSGRAVE, Alan. O falseamento e a metodologia dos programas de pesquisa científica. In: A crítica e o desenvolvimento do conhecimento: quarto volume das Atas do Colóquio Internacional sobre Filosofia da Ciência, realizado em Londres em 1965/ organizado por Imre Lakatos e Alan Musgrave. Traduzido por Octavio Mendes Cajado. São Paulo: Cultrix (Universidade de São Paulo), 1979.

MINAS GERAIS. Tribunal de Justiça de Minas Gerais. Apelação Cível 1.0194.10.011846-3/001, Relator(a): Des.(a) Otávio Portes, $16^{a}$ CÂMARA CÍVEL, julgamento em 07/08/2013, publicação da súmula em 19/08/2013

MIRAGEM, Bruno. Curso de direito do consumidor. 4. ed., São Paulo: Revista dos Tribunais, 2013.

MULHOLLAND, Caitlin Sampaio. A responsabilidade civil por presunção de causalidade. Rio de Janeiro: GZ, 2010.

PEREIRA, Caio Mário da Silva. Instituições de direito civil. 23, ed., Rio de Janeiro: Forense, 2010, v. I. 
PERNAMBUCO. Tribunal de Justiça de Pernambuco. EI 2385113 PE 0013311-93.2012.8.17.0000, $1^{\circ}$ Grupo de Câmaras Cíveis, Rel. Agenor Ferreira de Lima Filho, j. em 19/12/2012.

RIOS, Arthur E. S. Responsabilidade civil: os novos conceitos indenizáveis no projeto reale. In: Revista de Direito Civil, Imobiliário, Agrário e Empresarial. São Paulo: RT, v.10, n.36, 1986.

RIO DE JANEIRO. Tribunal de Justiça do Rio de Janeiro. APL 21759373920118190021, Comarca de Duque de Caxias, Rel. MARCELO CASTRO ANATOCLES DA SILVA FERREIRA, VIGÉSIMA TERCEIRA CÂMARA CÍVEL CONSUMIDOR, DJE 19/08/2014.

RIO GRANDE DO NORTE, Tribunal de Justiça do Rio Grande do Norte. AC 27394 RN 2001.0027394, $2^{a}$ Câmara Cível, Des. Cláudio Santos, DJE 09/07/2005.

Tribunal de Justiça do Rio Grande do Norte. AC 27394 RN 2001.002739-4, $2^{\text {a }}$ Câmara Cível, Des. Cláudio Santos, DJE 09/07/2005.

RIO GRANDE DO SUL. Tribunal de Justiça do Rio Grande do Sul. Recurso Cível nº 71003107364 RS, Rel. Luís Francisco Franco, J. em 23/11/2011.

. Tribunal de Justiça do Rio Grande do Sul. Apelação Cível: AC 70048594907

RS, Comarca de Porto Alegre, Rel. Des. Marilene Bonzanini, j. em 19/12/2012.

Tribunal de Justiça do Rio Grande do Sul. Recurso Cível No 71004762647 , Terceira Turma Recursal Cível, Turmas Recursais, Relator: Silvia Muradas Fiori, Julgado em 08/05/2014.

RODRIGUES, Lísia Carla Vieira. O código de proteção e defesa do consumidor e o novo código civil. São Paulo: Lumen Juris, 2008.

SÃO PAULO. Tribunal de Justiça de São Paulo. APL 10274982620158260100 SP 102749826.2015.8.26.0100, Rel. Roberto Mac Cracken, 22 ${ }^{a}$ Câmara de Direito Privado, DJE 16/12/2015.

SCHREIBER, Anderson. Novos paradigmas da responsabilidade civil: da erosão dos filtros da reparação à diluição dos danos. 6. ed., São Paulo: Atlas, 2015.

UNIÃO EUROPEIA, Diretiva CEE 374/85. 